\title{
Two-year Clinical Evaluation of One-step Self-etch Systems in Non-carious Cervical Lesions
}

\author{
Shisei Kubo ${ }^{a}$, Hiroaki Yokota ${ }^{b}$, Haruka Yokota ${ }^{b}$ and Yoshihiko Hayashi ${ }^{c}$
}

\author{
Address: ${ }^{a}$ Center for Clinical Education and Training, Nagasaki University Hospital of \\ Medicine and Dentistry, 1-7-1, Sakamoto, Nagasaki 852-8588, Japan \\ b Clover Dental Clinic, 3-17-13, Shodai, Sawara-ku, Fukuoka, Japan, 812-0012, \\ Japan \\ c Division of Cariology, Department of Developmental and Reconstructive \\ Medicine, Course of Medical and Dental Sciences, Nagasaki University Graduate \\ School of Biomedical Sciences, 1-7-1, Sakamoto, Nagasaki 852-8588, Japan
}

Short title: Two-year clinical evaluation of one-step self-etch systems

\section{Corresponding author:}

Name: Shisei Kubo

Address: Center for Clinical Education and Training, Nagasaki University Hospital of Medicine and Dentistry, 1-7-1, Sakamoto, Nagasaki 852-8588, Japan

Phone: $\quad 81-95-819-7757$

Fax: $\quad 81-95-819-7757$

E-mail: kubo@net.nagasaki-u.ac.jp

\section{Keywords:}

Randomized controlled trial; Two-year Clinical evaluation; One-step self-etch; Resin composite; Non-carious cervical lesions 


\title{
Two-year Clinical Evaluation of One-step Self-etch Systems \\ in Non-carious Cervical Lesions
}

\begin{abstract}
Objectives: This randomized controlled clinical trial evaluated the 2-year clinical performance of $\mathrm{S}^{3}$ Bond (S3) and G-Bond (GB) in 108 non-carious cervical lesions.

Methods: Twenty-three patients, 12 male and 11 female (mean age: 61.8 years, range: 30-79 years) regularly visiting the Nagasaki University Hospital of Medicine and Dentistry, participated in the study. Each patient received both materials randomly. All restorations (53 restorations for S3 and 55 restorations for GB) were placed by one dentist. The restorations were blindly evaluated by two examiners at baseline, 6 months, 1 and 2 years using modified USPHS criteria. The data were statistically analyzed using the Cochran Q test and Fisher's exact test.

Results: One restoration of each material was lost during 2 years. The only minor clinical problem was the integrity of the enamel margin. Slight marginal staining occurred adjacent to 11 restorations of both S3 and GB. There was no significant difference in the clinical performance between S3 and GB for each variable.
\end{abstract}

Conclusions: Under the protocol used in this study, S3 and GB have demonstrated an acceptable clinical performance up to 2 years. 


\section{,QURGXFWR}

A systematic review of current clinical trials has revealed that one-step self-etch systems are not as effective as conventional three-step total-etch systems and two-step self-etch systems. ${ }^{1)}$ In order to address this problem, several newer one-step self-etch systems with a relatively thin adhesive layer were, approximately $10 \mu \mathrm{m}$, developed a few years ago. ${ }^{2-11)}$ Introduction of a new technology and/or modification of a photoinitiator are used in these adhesive systems, and most of them are provided as a real one-bottle system. Comparison of the latest and the earliest versions of one-step self-etch systems from the same manufacturers showed a significant improvement of bond strengths and marginal sealing. ${ }^{5,6)}$ In addition, many studies have indicated that the newly developed one-step self-etch systems demonstrate comparable laboratory bond strengths to those of the two-step self etch systems. ${ }^{7-11)}$ Therefore, newer one-step self-etch systems would be expected to demonstrate good clinical performance. However, sufficient information about their clinical performance, which can provide the ultimate proof of clinical effectiveness, has not been available. ${ }^{2-4)}$

The aim of this randomized controlled clinical trial was to evaluate the 2-year clinical performance of resin composites in non-carious cervical lesions (NCCLs) restored with two newly developed one-step self-etch systems. 


\section{O DUUDOU DO HERG}

Twenty-three patients, 12 male and 11 female (mean age: 61.8 years, range: $30-79$ years) regularly visiting the Department of Conservative Dentistry, Nagasaki University Hospital of Medicine and Dentistry, participated in the study. No consideration was given to periodontal condition or parafunctional habits. All patients signed a consent form that had been approved by the Ethics Committee of Nagasaki University School of Dentistry.

A total of 108 cervical lesions, 93 NCCLs and 15 defective cervical resin composites placed in NCCLs, were restored with $\mathrm{S}^{3}$ Bond (S3: Kuraray Medical, Tokyo, Japan) or G-Bond (GB: GC Corp., Tokyo, Japan) in conjunction with a hybrid resin composite (Clearfil AP-X, Kuraray Medical) by the principal investigator. All but two patients had less than 3 restorations for each adhesive system. Each patient received both restorative groups which were randomly assigned. The distribution of the restorations was approximately equal except for the right side and the left side as shown in Tables 1 and 2.

The enamel wall of the cervical lesion was lightly roughened with a diamond bur at high speed with water cooling, and a short (approximately $1 \mathrm{~mm}$ ) enamel bevel prepared to increase surface area for bonding and to enhance aesthetics as reported by Meerbeek et al. ${ }^{12}$ Dentin walls were lightly ground with a steel round bur at slow speed without local anesthesia. No retention grooves were placed. In order to secure contamination-free access to the cavity, the adjacent gingiva was retracted by a gingival retraction cord, and the operating field was isolated with cotton rolls and a saliva ejector. 
The cavities were treated with S3 or GB according to the manufactures' instructions. For S3, the self-etch adhesive was applied to the cavity and left for 20 seconds. The solvent was evaporated with high pressure air for about 10 seconds which also thinned the adhesive layer. The adhesive was irradiated for 10 seconds with a conventional light-curing unit (New Light VL-II, GC Corp., Tokyo, Japan, output $>400 \mathrm{~mW} / \mathrm{cm}^{2}$ ). For GB, the self-etch adhesive was applied to the cavity for 10 seconds, strongly air-blown for about 5 seconds and light-cured for 10 seconds. The hybrid resin composite was placed in a single increment, contoured with a hand instrument, and light-cured for 40 seconds except for very large and/or deep lesions which were restored in several increments, and each increment cured for 20 seconds. The excess composite was trimmed and contoured with an ultrafine diamond bur with water coolant. The restorations were finished with ultrafine diamond points as a lap joint margin to avoid damaging surrounding tooth tissues, and polished with slow speed silicone points at a following visit.

The restorations were blindly evaluated at baseline, 6 months, 1 and 2 years by the second and third investigators, and further 1:1 color photographs taken. Slightly modified USPHS criteria were used (Table 3). In case of disagreement, a consensus was reached based on assessment of the photographs. In view of the need to observe the restorations in the future, no attempt was made to remove any visible excess by refurbishing.

Cochran Q test was used to compare the changes across the four time points (baseline, 6 
months, 1 year and 2 years). The comparison of two adhesive systems for each category was performed with Fisher's exact test. For all of the statistical analyses, a significant level was set at $\leq 0.05$.

\section{Results}

All patients were examined at each recall. However, one restoration for each adhesive system could not be examined as the teeth had been extracted. The clinical evaluations are summarized in Table 4. There were no significant differences in the clinical performances between S3 and GB for each variable. One restoration for each adhesive system was lost during 2 years. No secondary caries was detected around any restorations.

The only minor problem was enamel marginal integrity. The incidence of marginal staining increased with time as shown in Figure 1. Marginal staining occurred adjacent to 11 restorations for both S3 and GB after 2 years, and was significantly worse than at baseline. The extent of marginal stains also increased, but they were still superficial. The progress of marginal staining in typical cases is displayed in Figure 2 and 3. Marginal stains were observed only at the enamel margins of the restorations, regardless of the adhesive systems. The intraoral location (maxilla and mandible, right and left), tooth type, and lesion size and depth had no significant influence as presented in Table 5 and 6. In addition, marginal staining was found in 11 out of 23 patients. Interestingly, if more than two marginal stains 
occurred in the patient, at least one of them was associated with each adhesive system.

\section{Discussion}

Most one-step self-etch systems in current use were launched a few years ago. Therefore, only a few 1-year clinical reports are in the literature, ${ }^{2-4)}$ and no 2 -year clinical information is available. Previous two 1-year clinical trials of GB in NCCLs demonstrated $100 \%$ retention rates, though one was small sample size $(n=14)$ and the other employed prior enamel etching with phosphoric acid., ${ }^{3,4)}$ In the present study, S3 and GB showed one restoration failure at the 1-year and 2-year recall despite the use of the enamel bevel. However, both systems may fulfill the acceptance ADA guidelines in which no beveling is prescribed. $^{13)}$ Early loss of restoration is no longer the main cause of clinical failure when reliable adhesives are used. ${ }^{14-19)}$ The early retention failures may be due to a technical error. Although one-step self-etch systems are expected to reduce technique sensitivity by simplifying clinical steps, they are still technique sensitive. ${ }^{10,11,20,21)}$ Water is essential in one-step self-etching systems to ionize acidic monomer enough to dissolve the smear layer and demineralize dentin. ${ }^{22)}$ If water is not fully removed from the solvent containing adhesives, residual water interferes with optimal polymerization of the adhesive resin. ${ }^{23)}$ Therefore, air-drying may be a crucial step to ensure good clinical performance. ${ }^{10,11,20,21)}$ 
systems showed almost no marginal staining. ${ }^{3,4)}$ In the present study, enamel beveling and delayed polishing were employed according to the results of our previous laboratory studies, in which significant improvements of marginal sealing of self-etch adhesive systems were demonstrated. ${ }^{24,25)}$ However, the incidence and extent of marginal staining increased with time, as observed in two-step self etch systems, ${ }^{16,19)}$ and about $20 \%$ of the restorations had marginal stains only at the enamel margins after 2 years. In addition, lesion size, tooth type and location in the arch had no effect on marginal staining as reported by a recent clinical study. ${ }^{26)}$ These findings are probably due to the effectiveness of the adhesive systems used. S3 and GB show relatively high and similar bond strengths to both enamel and dentin. ${ }^{5,7)}$ However, it has been reported that self-etch systems show lower bond strength to unground intact enamel surface than to ground enamel ${ }^{27-29)}$ and a decrease in enamel bonding effectiveness with time. ${ }^{30-32)}$ Since the restorations were finished and polished as a lap joint margin to avoid damaging surrounding tooth tissues, the resin composite overlapping unground enamel adjacent to the cavity margin may easily be fractured by the etiological forces of NCCLs. Marginal staining was probably caused by the accumulation of stains at the marginal step or crevice rather than microleakage, as suggested by our previous study. ${ }^{16)}$ Besides, there seems to be patient factor in marginal staining. Although most restorations had small steps at the margins, marginal staining was found in half of the patients. Preference of food and beverage, smoking and tooth brushing habits may play a role in 
marginal staining.

Marginal staining is thought to be one of the first clinical signs that a resin composite restoration is prone to failure. ${ }^{2)}$ In addition, marginal staining may have become a more prominent reason for replacement as reported by Browning and Dennison. ${ }^{33)}$ However, marginal staining observed in this study appeared to be superficial, and may be easily removed by refurbishing. This is supported by other recent long-term clinical studies. ${ }^{15-19)}$ Retention is a very objective criterion, whereas evaluation of marginal staining is much more subjective. $^{34)}$ Mjör and Toffenetti ${ }^{35)}$ have reported that narrow gaps, crevices, ditches and "microleakage" do not lead to secondary caries. Therefore, monitoring of marginal staining is recommended to extend the longevity of the restorations as well as the teeth.

The relationship between marginal staining and marginal adaptation was indicated in many previous studies. ${ }^{15-19,26)}$ Indeed, the marginal stains were always noticed in combination with small marginal defects. The increase in number of small incisal marginal defects led to an increase in the number of restorations showing slight marginal discoloration. ${ }^{19)}$ However, not all the marginal defects resulted in marginal stains. ${ }^{3,16,19)}$ In addition, marginal adaptation is more subjectively evaluated and a less common reason for replacements of cervical resin composite restorations compared to secondary caries and marginal staining. ${ }^{3,33)}$ Detectable restoration margins (excess of material) may not be clinical failures, as reported by Türkün. ${ }^{26)}$ Therefore, in this study, the criterion for marginal 
adaptation was modified to be generous. This may account for better marginal adaptation compared to other studies. ${ }^{3,17,19)}$

The character of GB is a hydrophilic HEMA-free adhesive. Incorporation of HEMA into adhesives is advisable for improving monomer diffusion, decreasing the entrapment of droplets within the adhesive layer and preventing phase separation, ${ }^{36)}$ but may promote water sorption and hydrolytic degradation. ${ }^{32,37,38)}$ Possibly because of this, S3 demonstrated significantly or slightly higher bond strengths and less microleakage than GB in many laboratory studies, ${ }^{5-10,20,39)}$ whereas S3 tended to show poorer bonding durability than GB after 1 year water storage. ${ }^{32)}$ However, there were no significant differences in clinical performances between the adhesive systems up 2 years. Discrepancies between laboratory tests and clinical performances have been reported in many papers. ${ }^{14,18)}$ Only a well controlled clinical trial can provide the ultimate proof of clinical effectiveness. In addition, one-step self-etch adhesives behave as semi-permeable membranes due to their high hydrophilicity, allowing fluids to pass through and seriously jeopardizing bond durability. ${ }^{40)}$ More long-term clinical studies are required to provide the eventual determination of the effectiveness of the adhesives.

\section{Conclusion}

Under the protocol used in this study, although about $20 \%$ of the restorations had slight 
marginal staining, $\mathrm{S}^{3}$ Bond and G-Bond provided acceptable clinical effectiveness after 2 years of clinical service. In addition, there were no significant differences in clinical performances between the adhesive systems. 


\section{References}

1. Peumans M, Kanumilli P, De Munck J, Van Landuyt K, Lambrechts P, Van Meerbeek B. Clinical effectiveness of contemporary adhesives: A systematic review of current clinical trials. Dental materials 2005; 21: 864-881.

2. Perdigão J, Dutra-Corrêa M, Castilhos N, Carmo ARP, Anauate-Netto C, Cordeiro HJD, Amore R, Lewgoy HR. One-year clinical performance of self-etch adhesives in posterior restorations. American Journal of Dentistry 2007; 20: 125-133.

3. Kurokawa H, Miyazaki M, Takamizawa T, Rikuta A, Tsubota K, Uekusa S. One-year clinical evaluation of five single-step self-etch adhesive systems in non-carious cervical lesions. Dental Materials Journal 2007; 26: 14-20.

4. Burrow MF, Tyas MJ. Clinical trial of G-Bond all-in-one adhesive and Gradia Direct resin composite in non-carious cervical lesions-results at 1 year. Journal of Dentistry 2007; 35: 623-625.

5. Yokota H, Yokota H, Kubo S, Hayashi Y. Tensile bond strengths of one-step adhesive systems. The Japanese Journal of Conservative Dentistry 2005; 48 spring issue: 69.

6. Kubo S, Yokota H, Yokota H, Hayashi Y. Microleakage of cervical resin composites restored with one-step self-etch systems. Journal of Dental Research 2005; 84: Abstr. No. 3105. 
7. Ishikawa A, Shimada Y, Foxton RM, Tagami J. Micro-tensile and micro-shear bond strengths of current self-etch adhesives to enamel and dentin. American Journal of Dentistry 2007; 20: 161-166.

8. Sidhu SK, Omata Y, Tanaka T, Koshiro K, Spreafico D, Semeraro S, Mezzanzanica D, Sano H. Bonding characteristics of newly developed all-in-one adhesives. Journal of Biomedical Materials Research Part B; Applied Biomaterials 2007; 80: 297-303.

9. Knobloch LA, Gailey D, Azer S, Johnston WM, Clelland N, Kerby RE. Bond strengths of one- and two-step self-etch adhesive systems. Journal of Prosthetic Dentistry 2007; 97:216-222.

10. Spreafico D, Semeraro S, Mezzanzanica D, Re D, Gagliani M, Tanaka T, Sano H, Sidhu SK. The effect of air-blowing step on the technique sensitivity of four different adhesive systems. Journal of Dentistry 2006; 34: 237-244.

11. Sadr A, Shimada Y, Tagami J. Effects of solvent drying time on micro-shear bond strength and mechanical properties of two self-etching adhesive systems. Dental materials 2007; 23: $1114-1119$.

12. Van Meerbeek B, Kanumilli P, De Munck J, Van Landuyt K, Lambrechts P, Peumans M. A randomized controlled study evaluating the effectiveness of a two-step self-etch adhesive with and without selective phosphoric-acid etching of enamel. Dental materials 2005; 21: 375-383. 
13. Council on Dental Materials, Instruments and Equipment. Revised American Dental Association acceptance program guidelines for dentin and enamel adhesive materials. Chicago: American Dental Association; 1994.

14. Van Meerbeek B, De Munck J, Yoshida Y, Inoue S, Vargas M, Vijay P, Van Landuyt K, Lambrechts P, Vanherle G. Adhesion to enamel and dentin: current status and future challenges. Operative Dentistry 2003; 28: 215-235.

15. Tyas MJ, Burrow MF. Three-year clinical evaluation of One-step in non-carious cervical lesions. American Journal of Dentistry 2002; 15: 309-311.

16. Kubo S, Kawasaki K, Yokota H, Hayashi Y. Five-year clinical evaluation of two adhesive systems in non-carious cervical lesions. Journal of Dentistry 2006; 34: 97-105.

17. Akimoto N, Takamizu M, Momoi Y. 10-year clinical evaluation of a self-etching adhesive system. Operative Dentistry 2007; 32: 3-10.

18. Burrow MF, Tyas MJ. Five-year clinical evaluation of One-Up Bond F in non-carious cervical lesions. American Journal of Dentistry 2007; 20: 361-364.

19. Peumans M, De Munck J, Van Landuyt K, Lambrechts P, Van Meerbeek B. Five-year clinical effectiveness of a two-step self-etching adhesive. Journal of Adhesive Dentistry 2007; 9: 7-10.

20. Chiba Y, Yamaguchi K, Miyazaki M, Tsubota K, Takamizawa T, Moore BK. Effect of air-drying time of single-step self-application self-etch adhesives on dentin bond strength. 
Operative Dentistry 2006; 32: 233-239.

21. Hiraishi H, Breschi L, Prati C, Ferrari M, Tagami J, King NM. Technique sensitivity associated with air-drying of HEMA-free, single-bottle, one-step self-etch adhesives. Dental Materials 2007; 23: 498-505.

22. Tay FR, King NM, Chan K, Pashley DH. How can nanoleakage occur in self-etching adhesive systems that demineralize and infiltrate simultaneously? Journal of Adhesive Dentistry 2002; 4: 255-269.

23. Jacobsen T, Söderholm KJ. Some effects of water on dentin bonding. Dental materials 1995; 11: 132-136.

24. Kubo S, Yokota H, Watanabe T, Ohsawa M, Matsumoto H. Adhesive properties of Liner Bond II (KB-110) system. Part 1. Relationship between marginal seal and tensile bond strength. Japanese Journal of Conservative Dentistry 1994; 37: 1216-1223.

25. Yokota H, Sata Y, Kubo S, Hayashi Y. Effect of enamel bevel on microleakage of cervical resin composite restorations. Japanese Journal of Conservative Dentistry 1999; 42: 982-988.

26. Türkün LŞ. The clinical performance of one- and two-step self-etching adhesive systems at one year. Journal of American Dental Association 2005; 136: 656-664.

27. Kanemura N, Sano H, Tagami J. Tensile bond strength to and SEM evaluation of ground and intact enamel surfaces. Journal of Dentistry 1999; 27: 523-530. 
28. Miguez PA, Castro PS, Nunes MF, Walter R, Pereira PNR. Effect of acid-etching on the enamel bond of two self-etching systems. Journal of Adhesive Dentistry 2003; 5: 107-112.

29. Perdigão J, Gomes G, Duarte Jr S, Lopes MM. Enamel Bond strengths of pairs of adhesives from the same manufacturer. Operative Dentistry 2005; 30: 492-499.

30. Wang H, Shimada Y, Tagami J. Shear bond stability of current adhesive systems to enamel. Operative Dentistry 2004; 29: 168-175.

31. Frankenberger R, Tay FR. Self-etch vs etch-and-rinse adhesives: effect of thermo-mechanical fatigue loading on marginal quality of bonded resin composite restorations. Dental Materials 2005; 21: 397-412.

32. Torkabadi S, Nakajima M, Ikeda M, Foxton RM, Tagami J. Bonding durability of HEMA-free and HEMA-containing one-step adhesives to dentine surrounded by bonded enamel. Journal of Dentistry 2008; 36: 80-86.

33. Browning WD, Denison WD. A survey of failure modes in composite resin restorations. Operative Dentistry 1996; 21: 160-166.

34. Van Meerbeek B, Perdigão J, Lambrechts P, Vanherle G. The clinical performance of adhesives. Journal of Dentistry 1998; 26: 1-20.

35. Mjör IA, Toffenetti F. Secondary varies: a literature review with case reports. Quintessence International 2000; 31: 165-179.

36. Van Landuyt KL, De Munck J, Snauwaert E, Coutinho E, Poitevin A, Yoshida Y, Inoue S, 
Peumans M, Suzuki K, Lambrechts P, Van Meerbeek B. Monomer-solvent phase separation in one-step self-etch adhesives. Journal of Dental Research 2005; 84: 183-188.

37. Yiu CKY, King NM, Pashley DH, Suh BI, Carvalho RM, Carrilho MRO, Tay FR. Effect of resin hydrophilicity and water storage on resin strength. Biomaterials 2004; 25: $5789-5796$.

38. Ito S, Hashimoto M, Wadgaonkar B, Svizero N, Carvalho RM, Yiu C, Rueggeberg FA, Foulger S, Saito T, Nishitani Y, Yoshiyama M, Tay FR, Pashley DH. Effects of resin hydrophilicity on water sorption and changes in modulus of elasticity. Biomaterials 2005; 26: 6449-6459.

39. Owens BM, Johnson WW. Effect of single step adhesives on the marginal permeability of Class V rein composites. Operative Dentistry 2007; 31: 67-72.

40. Tay FR, Pashley DH, Suh BI, Carvalho RM, Itthagarun A. Single-step adhesives are permeable membranes. Journal of Dentistry 2002; 30: 371-382. 


\section{Acknowledgements}

This study was supported by Grant-in-Aid for Scientific Research from the Ministry of

Education, Culture, Sports, Science and Technology of Japan (16591918, 18791405, 18791406 and 20592230). The authors wish to thank Prof. Martin Tyas, University of Melbourne, for assistance in preparation of the manuscript. 


\section{Legends}

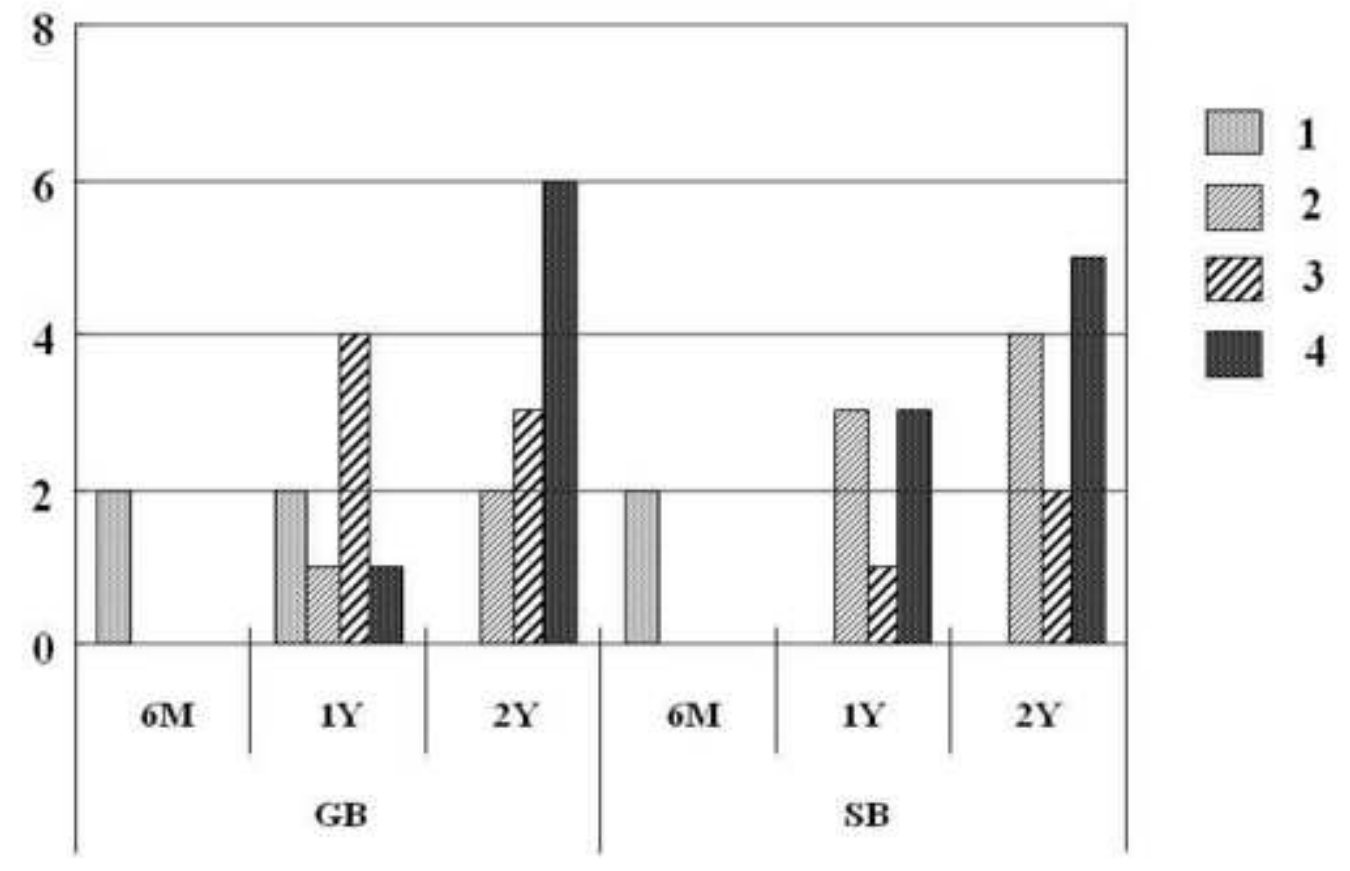

Figure 1

The incidence and extent of marginal staining. $\mathrm{n}$ : number of restorations which had marginal staining. 1: a sign of staining; 2: slightstaining; 3: clear localized superficial staining; 4: Clear linear superficial staining. 

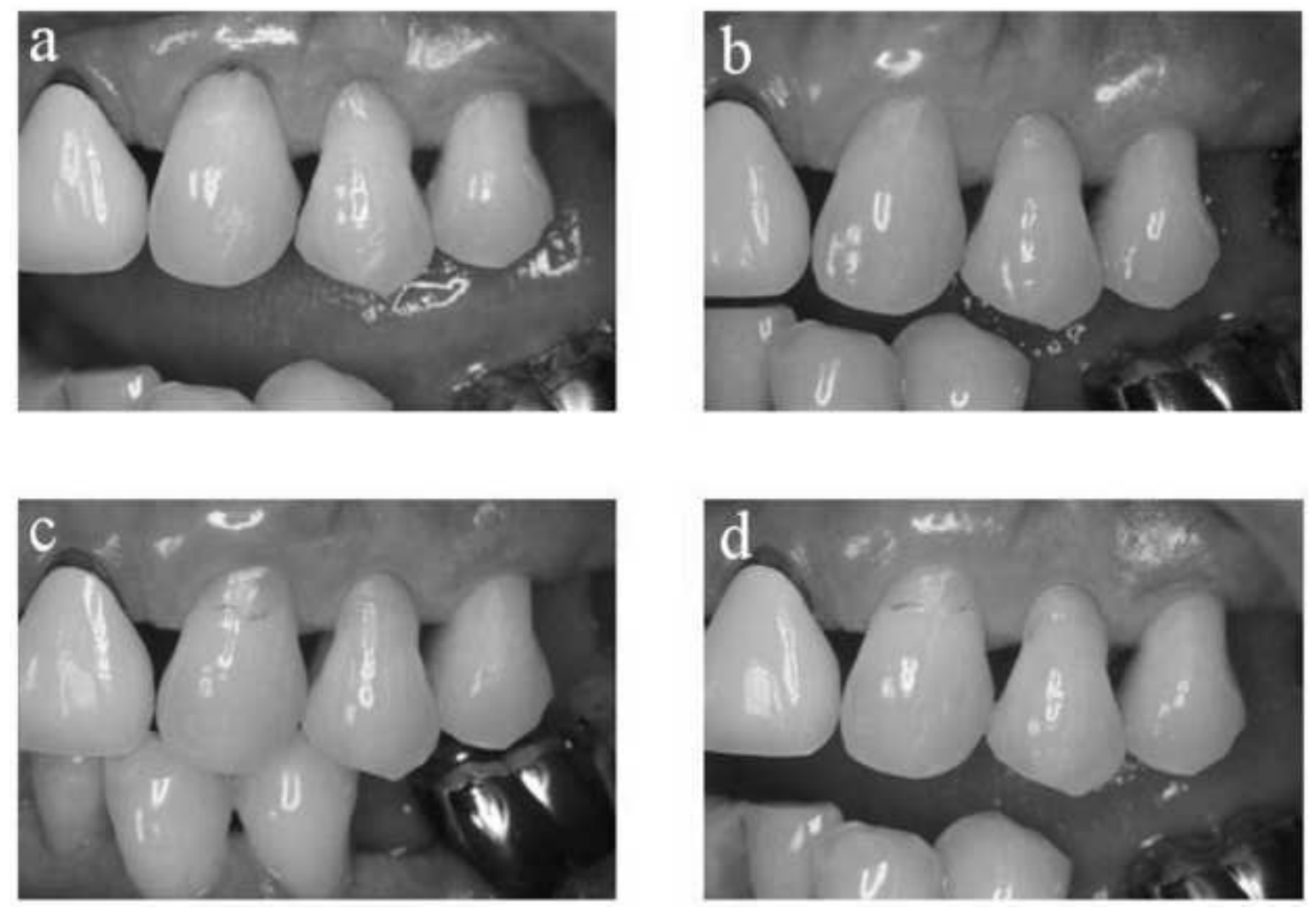

Figure 2

Progress of marginal staining. Cervical lesion in canine tooth was restored

with S3Bond and AP-X, and cervical lesions in premolars were restored with S3Bond and a flowable resin (Clearfil Flow FX): (a) baseline; (b)6-month recall; (c) linear superficialstaining was visible at 1-year recall; (d) excess resin composite at the middle of the incisal margin was fracturedat 2-year recall. 

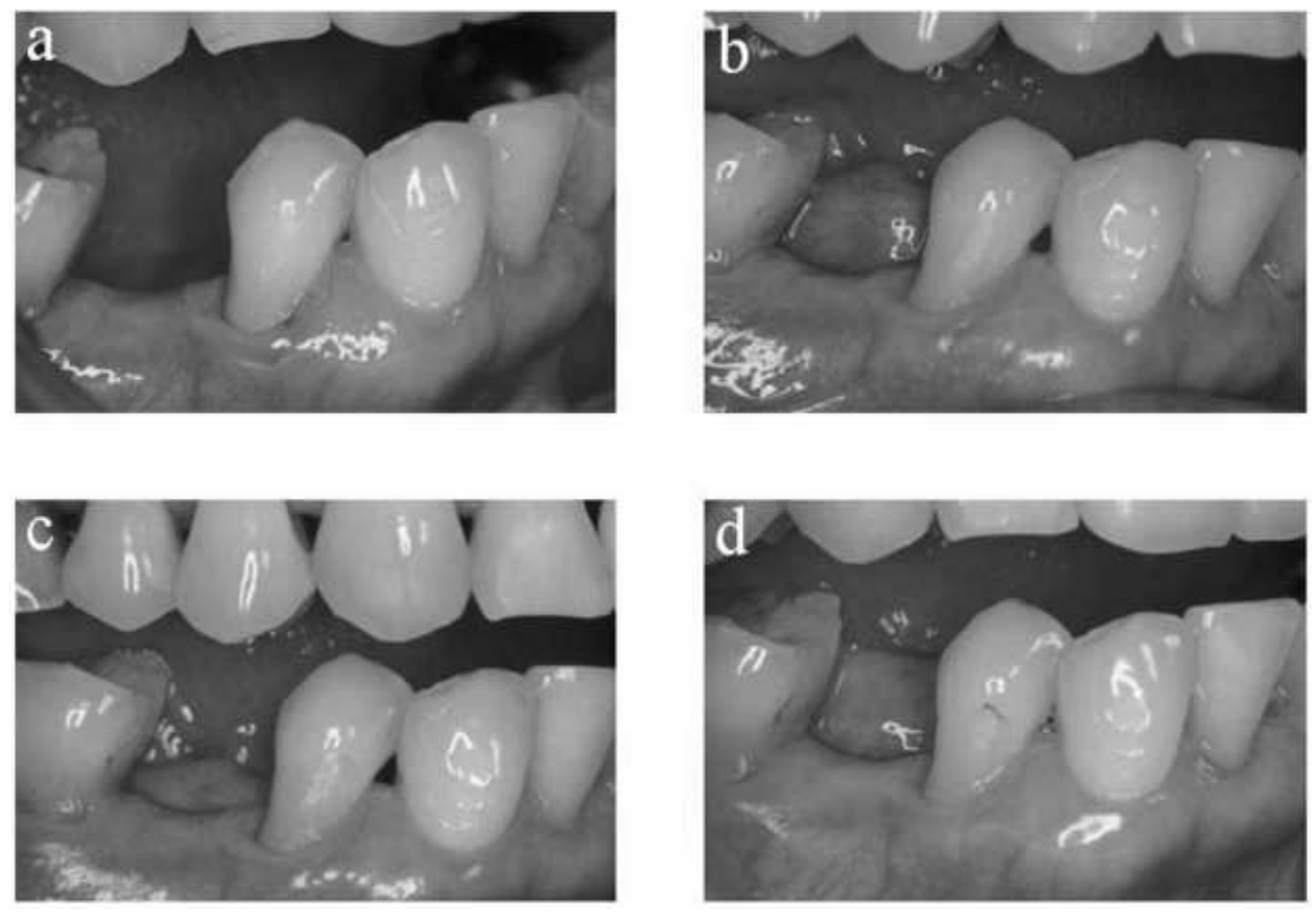

Figure 3

Progress of marginal staining. Cervical lesion in premolar tooth was restored

with G-Bond and AP-X: (a) baseline; (b) 6-month recall; (c) marginalstaining was suspectedat 1-year recall; (d) marginal stainingwas clearly visibleat 2-year recall. 
Table 1 Distribution of restorations

\begin{tabular}{|c|c|c|c|c|c|c|c|c|c|}
\hline \multirow{2}{*}{$\begin{array}{l}\text { Adhesive } \\
\text { systems }\end{array}$} & \multirow{2}{*}{ Arch } & \multicolumn{4}{|c|}{ Right quadrants (57) } & \multicolumn{4}{|c|}{ Left quadrants (51) } \\
\hline & & Molar & Premolar & Canine & Incisor & Incisor & Canine & Premolar & Molar \\
\hline \multirow{2}{*}{ S3 (53) } & Maxilla & 1 & 6 & 2 & 2 & 2 & 8 & 10 & 1 \\
\hline & Mandible & 1 & 7 & 0 & 0 & 7 & 3 & 3 & 0 \\
\hline \multirow{2}{*}{ GB (55) } & Maxilla & 2 & 8 & 5 & 7 & 2 & 2 & 9 & 1 \\
\hline & Mandible & 0 & 9 & 3 & 4 & 0 & 0 & 3 & 0 \\
\hline
\end{tabular}

( ), total number of restorations 
Table 2 Distribution of restorations by lesion size and depth

\begin{tabular}{|c|c|c|c|c|c|c|c|c|c|c|c|c|}
\hline \multirow{2}{*}{$\begin{array}{l}\text { Adhesive } \\
\text { systems }\end{array}$} & \multicolumn{3}{|c|}{ Small (23) } & \multicolumn{3}{|c|}{ Medium (52) } & \multicolumn{3}{|c|}{ Large (33) } & \multicolumn{3}{|c|}{ Total } \\
\hline & $\mathrm{S}$ & $\mathrm{M}$ & D & $\mathrm{S}$ & $\mathrm{M}$ & D & $\mathrm{S}$ & M & D & S & $\mathrm{M}$ & $\mathrm{D}$ \\
\hline S3 (53) & 13 & 0 & 0 & 4 & 20 & 2 & 2 & 9 & 3 & 19 & 29 & 5 \\
\hline GB (55) & 10 & 0 & 0 & 6 & 18 & 2 & 0 & 8 & 11 & 16 & 26 & 13 \\
\hline Total (108) & 23 & 0 & 0 & 10 & 38 & 4 & 2 & 17 & 14 & 35 & 55 & 18 \\
\hline
\end{tabular}

( ), total number of restorations

Small $(<1 \mathrm{~mm}$ in longitudinal width); Medium $(1-2.5 \mathrm{~mm})$; Large $(>2.5 \mathrm{~mm})$

$\mathrm{S}$, shallow $(<0.5 \mathrm{~mm})$; $\mathrm{M}$, moderate $(0.5-1.5 \mathrm{~mm})$; D, deep $(>1.5 \mathrm{~mm})$

No significant differences in distribution were found between adhesive systems. 
Table 3 Modified USPHS criteria for direct clinical evaluation

\begin{tabular}{|c|c|c|c|}
\hline \multirow{2}{*}{ Category } & \multicolumn{2}{|c|}{ Rating scale } & \multirow{2}{*}{ Criteria } \\
\hline & acceptable & unacceptable & \\
\hline \multirow[t]{3}{*}{ Retention } & $\mathrm{A}$ & & Retained \\
\hline & $\mathrm{B}$ & & Partially retained \\
\hline & & $\mathrm{C}$ & Missing \\
\hline \multirow[t]{3}{*}{ Marginal staining } & $\mathrm{A}$ & & None \\
\hline & $\mathrm{B}$ & & Superficial staining (removable, localized) \\
\hline & & $\mathrm{C}$ & Deep staining (not removable, generalized) \\
\hline \multirow[t]{2}{*}{ Recurrent caries } & $\mathrm{A}$ & & None \\
\hline & & $\mathrm{C}$ & Present \\
\hline \multirow[t]{3}{*}{ Marginal adaptation } & $\mathrm{A}$ & & $\begin{array}{l}\text { Undetectable margin or slight detectable step (catches } \\
\text { explorer going one way) }\end{array}$ \\
\hline & $\mathrm{B}$ & & Detectable crevice (catches explorer going both ways) \\
\hline & & $\mathrm{C}$ & Obvious crevice or fracture \\
\hline \multirow[t]{3}{*}{ Gingival response } & $\mathrm{A}$ & & Absence of inflammation \\
\hline & $\mathrm{B}$ & & Mild inflammation \\
\hline & & $\mathrm{C}$ & Moderate or sever inflammation \\
\hline Other failures & $\mathrm{A}$ & & None \\
\hline (color change, wear, etc) & & $\mathrm{C}$ & Present \\
\hline
\end{tabular}


Table 4 Summary of direct evaluations at 2-year recall

\begin{tabular}{|c|c|c|c|c|c|}
\hline \multirow{2}{*}{ Category } & \multirow{2}{*}{$\begin{array}{l}\text { Adhesive } \\
\text { systems }\end{array}$} & \multicolumn{2}{|c|}{ Acceptable } & \multirow{2}{*}{$\begin{array}{c}\text { Not acceptable } \\
\text { C }\end{array}$} & \multirow{2}{*}{ p-values } \\
\hline & & A & B & & \\
\hline \multirow[t]{2}{*}{ Retention } & S3 & $51(98)$ & 0 & $1(2)$ & \multirow{2}{*}{1.000} \\
\hline & GB & $53(98)$ & 0 & $1(2)$ & \\
\hline \multirow[t]{2}{*}{ Marginal staining } & S3 & $41 \quad(79)$ & $11(21)$ & 0 & \multirow{2}{*}{1.000} \\
\hline & GB & 42 (79) & $11(21)$ & 0 & \\
\hline \multirow[t]{2}{*}{ Recurrent caries } & $\mathrm{S} 3$ & $51(100)$ & - & 0 & \multirow{2}{*}{1.000} \\
\hline & GB & $53(100)$ & - & 0 & \\
\hline \multirow[t]{2}{*}{ Marginal adaptation } & S3 & $51(100)$ & 0 & 0 & \multirow{2}{*}{1.000} \\
\hline & GB & $53(100)$ & 0 & 0 & \\
\hline \multirow[t]{2}{*}{ Gingival response } & $\mathrm{S} 3$ & $51(100)$ & 0 & 0 & \multirow{2}{*}{1.000} \\
\hline & GB & $52 \quad(98)$ & $1(2)$ & 0 & \\
\hline Other failures & $\mathrm{S} 3$ & $51(100)$ & - & 0 & \multirow{2}{*}{1.000} \\
\hline (color change, wear, etc) & GB & $53(100)$ & - & 0 & \\
\hline
\end{tabular}

Each entry represents $\mathrm{n}(\%)$.

For each adhesive, one restoration was lost by extraction because of periodontal disease between 1 and 2 year-r 
Table 5 The influence of location and tooth type on marginal staining

\begin{tabular}{|c|c|c|c|c|c|c|c|c|}
\hline \multirow{2}{*}{ Arch } & \multicolumn{4}{|c|}{ Right } & \multicolumn{4}{|c|}{ Left } \\
\hline & Molar & Premolar & Canine & Incisor & Incisor & Canine & Premolar & Molar \\
\hline Maxilla & $1 / 3$ & $3 / 14$ & $3 / 7$ & $3 / 9$ & $0 / 4$ & $3 / 10$ & $2 / 19$ & $0 / 2$ \\
\hline Mandible & $0 / 1$ & $6 / 16$ & $0 / 3$ & $0 / 4$ & $0 / 7$ & $0 / 3$ & $1 / 6$ & $0 / 0$ \\
\hline
\end{tabular}

number of restorations with marginal staining / total number of restorations 
Table 6 The influence of lesion size and depth on marginal staining

\begin{tabular}{lcccc}
\hline \multirow{2}{*}{ Depth } & \multicolumn{4}{c}{ Size } \\
& Small & Medium & Large & Total \\
\hline Shallow & $2 / 23$ & $2 / 10$ & $0 / 2$ & $4 / 35$ \\
Moderate & $0 / 0$ & $8 / 38$ & $6 / 17$ & $14 / 55$ \\
Deep & $0 / 0$ & $1 / 4$ & $3 / 14$ & $4 / 18$ \\
Total & $2 / 23$ & $11 / 52$ & $9 / 33$ & $22 / 108$ \\
\hline
\end{tabular}

number of restorations with marginal staining / total number of restorations 